\title{
29 WHY DO PATIENTS WITH HAEMATOLOGICAL MALIGNANCIES DIE IN HOSPITAL? QUALITATIVE FINDINGS FROM A UK STUDY
}

Dorothy McCaughan, Eve Roman, Alex Smith, Debra Howell. Epidemiology and Cancer Statistics Group, Health Sciences, University of York, UK

\subsection{6/bmjspcare-2016-001204.29}

Introduction Research suggests most people would prefer to die at home, ${ }^{1}$ yet patients with haematological malignancies (leukaemia, lymphoma, myeloma) die in hospital more often than those with other conditions, and there is little evidence to explain this. ${ }^{2-4}$

Aim To explore perceptions about why hospital deaths predominate.

Methods Qualitative interviews with 46 clinicians who care for blood cancer patients and 10 relatives of deceased patients. Interviews were audio-taped, transcribed and analysed for thematic content. An inductive approach was used to code and classify data, which included: familiarisation with the data; attribution of individual codes; collating codes into themes; and interpretation by seeking meaning, salience and connections.

Results Hospital deaths are largely determined by the disease characteristics and its trajectory, including: intensive, toxic treatment; propensity for sudden, unexpected deterioration/ death; and blurred transitions, where patients "dip up and down", causing difficulties predicting prognosis and determining when to stop treatment. While haematology staff questioned "the rhetoric that the only good death is a home death', and recognised that hospital deaths were appropriate and desired by some, others considered home death generally more preferable. Hospital admission/deaths were often precipitated by unrealistic expectations about home death and lack of 24-hour community care to facilitate this.

Conclusion The complex, unpredictable nature of haematological malignancies biases towards hospital deaths. Provision of high quality, hospital-based end-of-life care is essential to patient/caregiver experiences. While some choose to die in hospital, others dying there may have different preferences. Community services should be adequately resourced to enable patients to make meaningful, deliverable choices about their end-of-life care.

\section{REFERENCES}

1 House of Commons Health Committee. End of life care: Fifth report of session, 2014-2015. London: The Stationery Office Limited; 2015

2 National Cancer Intelligence Network. Where do patients with blood cancers die? London: Public Health England; 2010

3 Howell DA, Roman E, Cox $\mathrm{H}$, et al. Destined to die in hospital? Systematic review and meta-analysis of place of death in haematological malignancy. BMC Palliat Care 2010;9(9):1-8

4 Howell DA, Wang HI, Smith AG, et al. Place of death in haematological malignancy: variations by disease sub-type and time from diagnosis to death. BMC Palliat Care 2013;12(42):1-8 